\title{
THE LETTER OF APPLICATION IN VOCATIONAL SELECTION
}

By A $T$ Poffenberger and $V . H$ Vartanian

In our search for tests for purposes of vocational selection, there has been a tendency to turn our backs upon some of the more primitive methods. Among these is the letter of application. As commonly used, it is undoubtedly ineffective There has been lacking the check upon results so necessary for determining the value of any measure Letters of application are usually received by one individual who reads them and chooses the one or two that seem to him to represent the desirable aplicants Whether he has chosen the best or whether he has turned the best away, he may never know, because he has only the persons retained as the record of his choice. Perhaps his own judgment is not to be relied upon $H_{1}$ reaction to letters may be influenced by foolish prejudices either temporary or permanent. He might judge differently if he examined the letters again a week later; or the choice might be different if he were to ask the cooperation of ten of his business associates in evaluating the letters, and were to accept the results of their combined judgment. In spite, however, of its shortcomings as commonly used, the letter of application is still considered a part of the routine of the employment process by many institutions and individuals.

Now a letter of application, if really written by the applicant, might show many characteristics that are important and otherwise difficult to measure, such as ability to express oneself clearly and logically, neatness, good taste, seriousness of purpose and care for details. If checked up by some means as to accuracy of statement, it might conceivably serve as a good measure of honesty and integrity.

This report is intended to show to what extent the letter of application might be of service in vocational selection. One other study of similar nature will be briefly reviewed. Walton ${ }^{1}$ studied the judgments, by fifty business and professional men, of twenty-five letters of application for a position as bookkeeper Although there was no check upon

I An unpublished Master's thesis in the department of psychology of Columbia University. 
the qualifications of the applicants, some interesting results were obtained.

1 Consistency of the Judges. Each judge arranged the letters in an order of merit twice, the interval between arrangements being long enough to rule out the factor of memory. The consistency of the judges is shown by the coefficients of correlation ${ }^{2}$ between the first and second arrangement for each judge The following figures show the average of the coefficients and their range for each of the four traits, intellgence, tact, reliability and neatness:

$\begin{array}{lcc} & \begin{array}{c}\text { Relation between first } \\ \text { and second arrangement }\end{array} & \begin{array}{c}\text { Range of } \\ \text { Coefficients }\end{array} \\ \text { Intelligence } & 537 & .08-72 \\ \text { Tact } & 473 & 18-72 \\ \text { Relrability } & 474 & .20-.73 \\ \text { Neatness } & 600 & 14-91\end{array}$

The figures show that the consistency of judgment varies with the trait, that individuals differ in their consistency in making such judgments; and that there are considerable differences among people in their ability to judge the trait itself from a letter.

2. Agreement Among the Judges. The judges agree more closely concerning the presence of some traits than of others when they are sought in letters of application. Those upon which there is most agreement are intelligence and tact, those upon which there is least agreement are reliability and neatness.

3. Correlation Between Trats. The coefficients of correlation between traits are given in the following figures:

$\begin{array}{lr}\text { Intelligence and Tact } & 52 \\ \text { Intelligence and Reliability } & .91 \\ \text { Intelligence and Neatness } & .82 \\ \text { Tact and Reliability } & 91 \\ \text { Tact and Neatness } & .85 \\ \text { Reliability and Neatness } & 84\end{array}$

They support what has frequently been reported, namely, that in such judgments it is not possible to react separately to particular traits, but rather the judge is governed by his general impression. Thorndike has aptly called this the "halo" effect.

4. Judgment of Good and Poor Letters. There is closer agreement upon the poor than upon the good letters for three of the traits judged, as shown by the following average devia-

\footnotetext{
${ }^{2}$ All coefficients of correlation presented in this report were obtained by the Spearman formula
} 
tions for the judgments in the case of the first and last letters.
A $D$ for the 25th letter
A $D$ for the first letter
402
584

If this were found to hold consistently, it would be advisable to select the best by elimination of the worst rather than by direct selection of the best

The experiment to be reported here was performed several years ago. It differs from that of Walton in that it provided a check against which the judgments of the letters couid be evaluated Twenty-five students in the senior class of a tranning school for religious workers in New York City wrote letters of application for a position as religious worker in a certain section of the city These letters just as received were given in turn to twelve members of the staff of the Union Theological Seminary, New York City, with the request that they arrange them in an order according to the degree to which they indicated general fitness for the position

The measures which were to serve as checks against the letters were obtained as follows: Five teachers from the staff of the training school furnished three separate arrangements of twenty-five individuals according to the degree to which they possessed the three traits, general ability, intelligence and tact These three traits were thought by the teachers to cover the qualities most needed for success in the religious work In addition each member of the group of applicants arranged his twenty-four associates and himself in an order for each of these three traits The conditions for such est1mates were especially good, as the school is small and every teacher has very close association with his students; and the students themselves are more closely associated than are students in the ordinary college. ${ }^{3}$

We have then for purposes of comparison the following material

a--Estımates of general fitness determined from the letters.

$\mathrm{b}$-Estimates of general ability by the teachers

c-Estimates of intelligence by the teachers

d-Estimates of tact by the teachers

e-Estimates of general ability by the associates

$\mathrm{f}$-Estimates of intelligence by the associates

$\mathrm{g}$-Estimates of tact by the associates

${ }^{3}$ The average deviations of the positions assigned the individuals ranged from 1 to 5 , where the total possible range is twenty-five. The average of these average deviations in the case of intelligence was 3.7 According to the formula presented by Berliner in the $J$. of $A p p l$ Psychol, 2, 1918, pp. 236ff, the average of all of the deviations for arrangements by chance would be 6.25 . 
1 Correlation Between Traits. When the individuals are judged directly by the teachers and associates, the traits are found to be related as follows

$\begin{array}{ll}\text { General ability and intelligence } & 95 \\ \text { General ability and tact } & 82 \\ \text { Intelligence and tact } & 86\end{array}$

These coefficients are about the same as those found by Walton where the letters were judged, and they indicate the tendency to judge from general impression, as previously stated. It would seem that, for practical purposes, a judgment for general fitness would be better than judgments for special traits, as such a task would be much less likely to confuse the judges

2 Relation Between the Estmates of Teachers and Associates The following coefficients show the relation between the average arrangement of the twenty-five individuals by the teachers and by the associates for the three traits

$\begin{array}{lc} & \begin{array}{c}\text { Relation between teachers' } \\ \text { and associates' estimates }\end{array} \\ \text { General ability } & 90 \\ \text { Intelligence } & 83 \\ \text { Tact } & 59\end{array}$

The coefficients for general ability and intelligence are rather high, while that for tact is very much lower This is, doubtless, due to the fact that the associates and teachers have different criteria of tact There are no objective measures of this trait to form a common basis for judgment such as school grades would afford for intelligence or general ability

3 Estimates of the Letters The average deviations for the positions assigned to the individual letters ranged in size from 15 to 67 positions, where the total range of positions is twenty-five This range is somewhat greater than in the case of the direct estimation of the individuals for intelligence (1-5) The average of all the deviations for all leiters is 4.2 positions, where it would be 625 if the arrangements were chance arrangements (See note above) This is somewhat higher than the average of the deviations for the direct est1mation of individuals for intelligence, namely 37 . That is, there is a closer agreement in judging the individuals than in judging therr letters

As reported by Walton the agreement among the judges 1s closer for the poorest than for the best letter (A D of 15 as compared with A. D 22), but as the difference is small and the relation is reversed for the next poorest and the next best, it has no particular significance. 
4. Relation Between Estimates of Letters for General Fitness and Direct Estimates of the Individuals. The following figures show the correlations between the estimates of the letters and the estımates of the individuals for the three traits, general ability, intelligence, and tact by teachers and associates

General ability (Combined estımates of teachers and associates)

and letters................, .50

General ability (Teachers' estumates) and letters... $\ldots \ldots . . .56$

General ability (Associates' estimates) and letters . . . . . .46

Intelligence (Combined estimates of teachers and associates) and letters .. . . ... . . .44

Intelligence (Teachers' estimates) and letters . . ... . . .58

Intelligence (Associates' estimates) and letters . ... ${ }^{\circ} .44$

Tact (Combined estimates of teachers and associates) and letters .22

Tact (Teachers' estımates) and letters $\quad . \quad \ldots \quad . . .20$

Tact (Associates' estımates) and letters $\quad . .18$

General ability, intelligence and tact (Combined estimates of teachers and associates) and letters

General ability and intelligence (Combined estımates of teachers and associates) and letters

General ability and intelligence (Teachers' estımates) $\ddot{\circ}$ and letters

General ability and intelligence (Associates' estimates) and letters

A consideration of these coefficients of correlation leads to the following observations.

Coefficients involving tact are the lowest Walton, however, found rather close agreement among the judges for this trait It has been noted earlier in this paper that the correlation between teachers' and associates' estimates of this trait was low. On the whole it seems unlkely that letters will provide a good measure of this trait.

Correlations between teachers' estimates and the letter estimates are higher than those between associates' estımates and the letter estimates Various reasons for this difference suggest themselves, e.g, that the teachers are better judges, or that the two teacher groups (the judges of the letters being teachers) take a more similar attitude toward the task than teachers and associates would be expected to take.

Of the estimates by the teachers, that of general ability and intelligence both correlate fairly high with the average estimates of the letters, namely .56 and 58 , in comparison with the usual test correlations. According to Thorndike, a general intelligence test could not be expected to correlate with success in college to a higher degree than about .60 .

There is little relation between the estimation of tact from the letters and from the individuals themselves, whether the teachers or the associates are the judges. 
If the average positions assigned for the different traits are combined and an order be determmed therefrom, the correlation with the order for the letters is not rased above that for one trait alone. The same is true when combinations of two traits are correlated with the letter order

5 Relation Between Individual and Group Judgments The coefficients of correlation of individual arrangements of the letters with the average order for general ability obtained from the associates are as follows in order of size

$.18, .24, .26, .34, .34,40, \quad 40, \quad 40, .46, .46, \quad .48, \quad .52$ The average of these coefficients is .37 . Now the coefficient of correlation of the average order for the letters (group judgment) with the average order of the individuals judged by their associates for general ability is 46 Thus the group judgment is somewhat better than the average of the individual judgments Only two of the individuals show a higher correlation than that of the group Therefore, although one might find a judge who would do better than the group judgment, the group judgment would be safer unless one had some means of knowing the good judges beforehand

Now if the same comparisons are made with the teachers' arrangement instead of the associates' arrangement, the following coefficients are obtaned, in order of size:

$.24, \quad .30, \quad .34, \quad .38, \quad 40, \quad 46, \quad .49, \quad 49, \quad .53, \quad 56, \quad .57$

The correlation for the average arrangement of the letters with the teachers' estimates is 56 , as compared with the average of the individual coefficients 435

6 Consistency of the Judgments of the Letters. Repeated arrangements of the letters by the same judges were not obtained, because the original letters of application were used and they had become solled and worn with much handling Since the conditions for judgment were very much the same as those in Walton's experiment we may assume that the consistency would be about the same

7. Basis for Estimation of the Letters. There were numerous criteria for forming judgments of the letters, such as choice of paper, general style of the letter, handwriting, marginal spacing, line spacing, neatness, and mode of expression. There was also the actual content of the letter, such as the description of previous training, interest in the work, reasons for making application for the position, etc No effort has been made to determine the importance of these various factors, although it would seem quite worth while to do so The more mechanical factors such as those first listed could be 
eliminated from the judgment, by presenting uniformly typewritten copies of the letters The criteria would then be largely content and mode of expression. In the light of the usual requirement that letters of application be written in the applicant's own handwriting, it would be interesting to know the importance of these factors.

Conclusion Individual differences in the ability to judge fitness from letters of application must be recognized Some traits are much more clearly indicated in letters than others, while certan traits like tact can probably not be measured in letters The combined estimates of a group of judges is more to be relied on than the judgment of one individual unless there is some means of picking the good judge Some of the correlations here reported are as high as has been expected from the use of intelligence and other more specialized tests as measures of fitness for practical purposes

The letter of application is not to be relied on even for a prelıminary weeding out of candidates unless the ordinary safeguards against personal bras, etc., be used But if treated and controlled as a test method it should be of service in vocational selection It might be made to give a composite picture of neatness, intelligence, schooling. truthfulness, interest in details, ambition and many other of the character traits for which at present there are no adequate measures. 